\title{
Fabricating Images at the Color Factory
}

\section{Lida Zeitlin Wu}

https://doi.org/10.15664/fcj.v0i17.2074

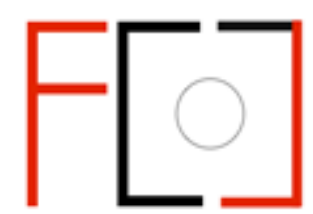

Frames Cinema Journal

ISSN 2053-8812

Issue 17 (Jun 2020)

http://www.framescinemajournal.com

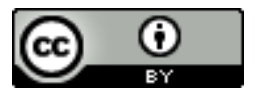




\section{Fabricating Images at the Color Factory Lida Zeitlin Wu}

"You made it to the moon!"

These were the words that welcomed me as I turned the corner into the final room at the Houston location of the Color Factory, a self-described "interactive exhibit that celebrates the discovery, serendipity and generosity of color". ${ }^{1}$ The speaker was one of the exhibition's many "greeters" - essentially docents who supervise its various participatory installations. Clad in an aggressively purple jumpsuit, the greeter explained to me that I was to take off my shoes before entering the ball pit, and to turn the volume up on my phone ('You can't imagine how many we've lost in there!'). Having already been to the New York location, I knew what to expect: every rendition of the Color Factory culminates in a ball pit of monumental proportions. Exhibition goers wade their way into the pit, lie on their backs, and pose for automated photos taken by cameras mounted on the ceiling. But whereas the ball pits in San Francisco and New York were bright yellow ("in honour of Michael Stanley, the man who only wore yellow") and powder blue (matched to a Pantone swatch of a New York summer sky), respectively, the Houston location's was an almost phosphorescent silvery white. The surrounding walls and ceilings were black, and twinkling dots of light hovered above the pit. Sponsored by NASA, whose headquarters are located in Houston, to commemorate their fiftieth anniversary, the ball pit (titled simply To the Moon) is one of many nods to local geography in an exhibition that claims to be site-specific. In addition to the floating, weightless experience of the ball pit, visitors can listen to a recording of the 1969 Apollo 11 moonwalk. This integration of sound also echoes a central theme of the pop-up across locations: namely, to create a multisensory experience linked to environmental colour. For a moment, submerged neck-deep in the pit, gazing up above at the fibre-optic lights, I could almost believe that I was in zero-gravity - until the aerial camera's flash shattered this illusion. 


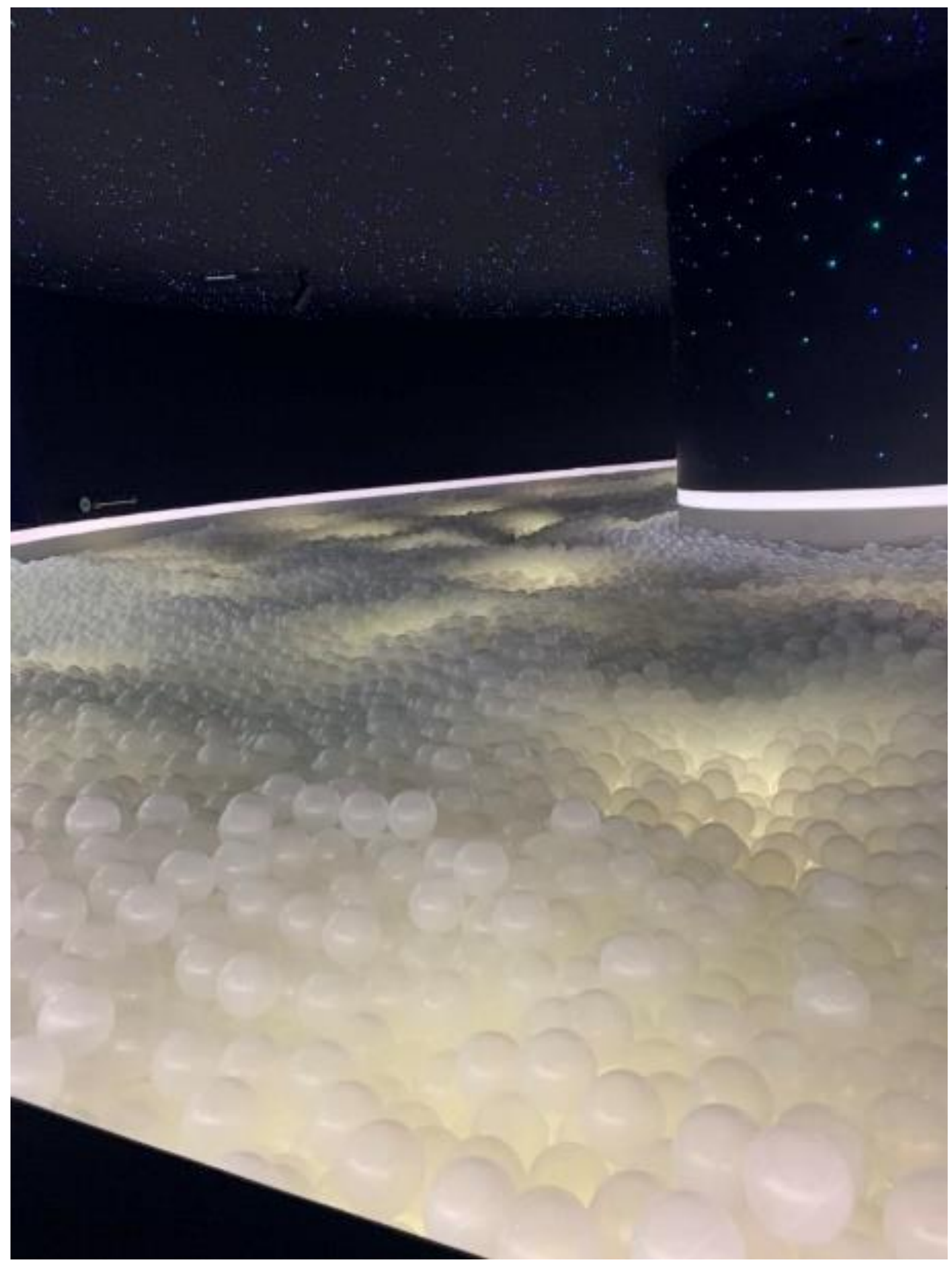

Figure 1: To the Moon, an immersive ball pit in Houston featuring fibre-optic lights and recorded sound. Sponsored by NASA. 


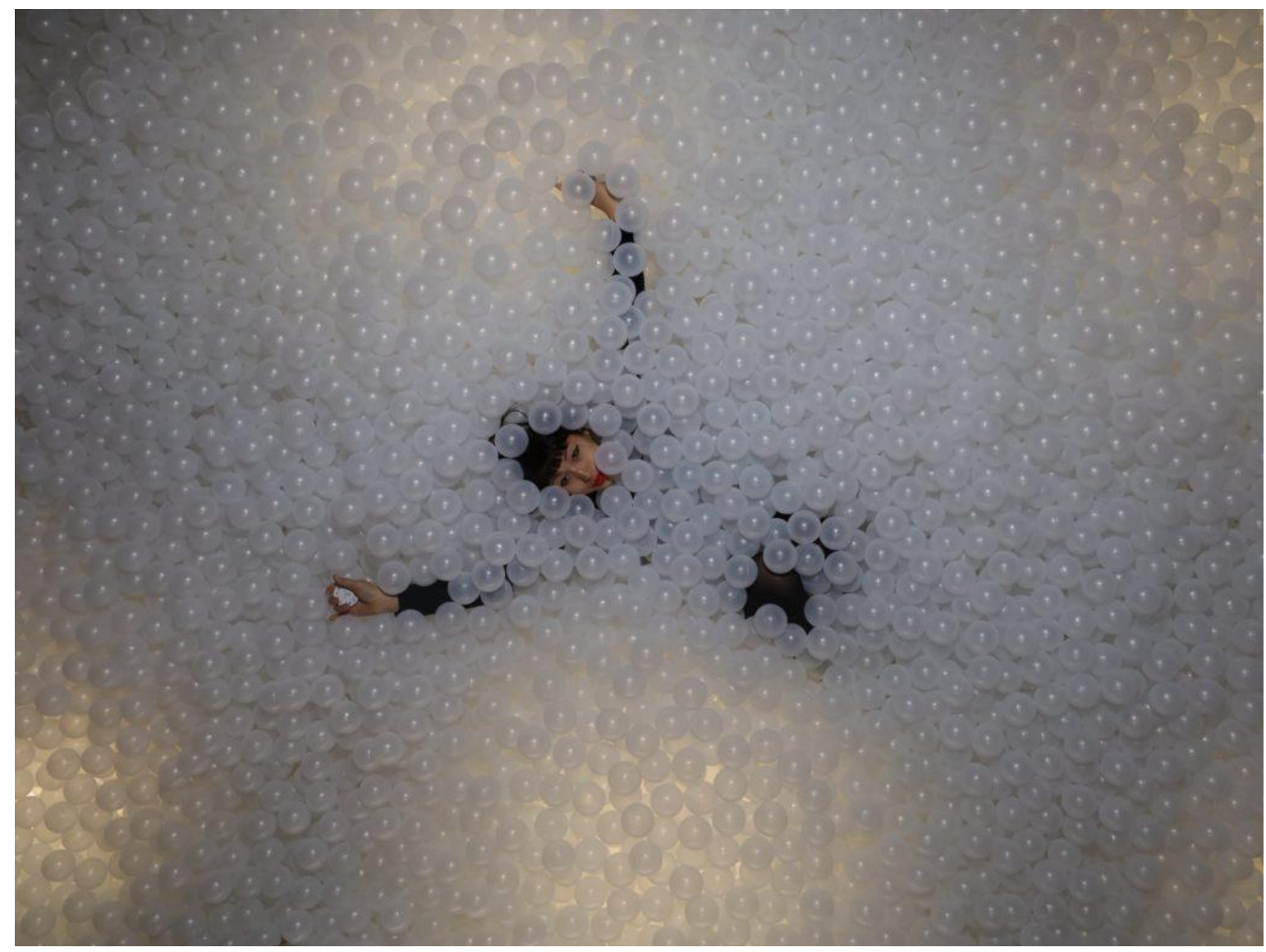

Figure 2: To the Moon, an immersive ball pit in Houston featuring fibre-optic lights and recorded sound. Sponsored by NASA.

Founded by event planner Jordan Ferney, San Francisco-based artist Leah Rosenberg, and designer Erin Jang, the Color Factory debuted in San Francisco in 2017, where it was only supposed to run for one month. Instead, the exhibition lasted for nearly nine months (I couldn't get tickets because it was completely sold out), and by popular demand, moved to New York the following year, and opened a new location in Houston in 2019. The space is a 20,000 square foot warehouse where every visible surface has been covered with abstract patterns of brightly saturated colour. Mounted cameras take photos or Boomerangs of participants and send them directly to their email so that they can then be posted on social media platforms, earning such pop-ups the moniker of "Instagram Exhibitions". ${ }^{2}$ Such experiences, which are designed with digital reproducibility in mind, are part of an attention economy that turns sensory pleasure into data by existing in two places simultaneously: the physical gallery space and on social media. While few visitors to the Color Factory, where one can dive into piles of confetti or eat colour-coded French macarons on a rotating conveyer belt, are likely to see it as anything other than pure entertainment or spectacle, the exhibition can be seen as an almost perverse quantification of the body through algorithmic colour. Though the pop-up at first glance seems to foster unmediated physical intimacy through activities that emphasise human connection, it actually renders colour further abstract and quantifiable while simultaneously normalising selfsurveillance: ultimately participants must adapt to the infrastructure of this environment, and by extension, to increasingly regulated understandings of selfhood. 
The phenomenon of the pop-up event or visual spectacle is by no means a new phenomenon we might think of nineteenth-century World's Fairs that showcased new developments in electric lighting, the "happenings" of Fluxus in the 1960s and more recently, installations such as Yayoi Kusama's Infinity Rooms or Random International's Rain Room (2012). These installations, where photography is encouraged, mark a clear departure from site-specific performances such as Marina Abramovic's 512 Hours (2014), where audience members had to store their camera phones in lockers before entering the gallery. Because the Color Factory constantly announces its hyper-mediated nature, it is highly relevant for thinking about the digitally mediated nature of experiences that announce themselves as discrete "events." Unlike the televised media event, where "the referent becomes indissociable from the medium" (is the event being broadcast deemed important because it is considered newsworthy, or because television must assert its importance by covering breaking news stories?), the pop-up installations of the digital age emphasise that such "experiences" must be first and foremost experienced in the flesh. ${ }^{3}$ This focus on in-person interactivity and the notion that a full and memorable experience must activate all five senses is inseparable from widespread anxieties that digitization will eventually render daily existence increasingly detached, impersonal, and ephemeral.

In an effort to bridge the gap between physical and virtual space, the Color Factory takes part in a long-established tradition of colour-based synesthesia, most clearly seen with regard to sound. In New York, visitors are encouraged to play comically-large xylophones with coloured keys and to experiment with different harmonies; the most "harmonious" intervals, such as the first and fifth notes of a scale, correspond to specific colour combinations. ${ }^{4}$ Here, centuries of sound and colour-based synesthesia are on full display, with intertexts ranging from Newton's division of the spectrum into musical intervals to a fin-de-siècle fascination with colour and music ${ }^{5}$ Like the colour-organ performances of the 1920s, the Color Factory's sound-based installation aims to create a multisensory atmosphere that blurs the boundaries of colour, light, and music. ${ }^{6}$ 


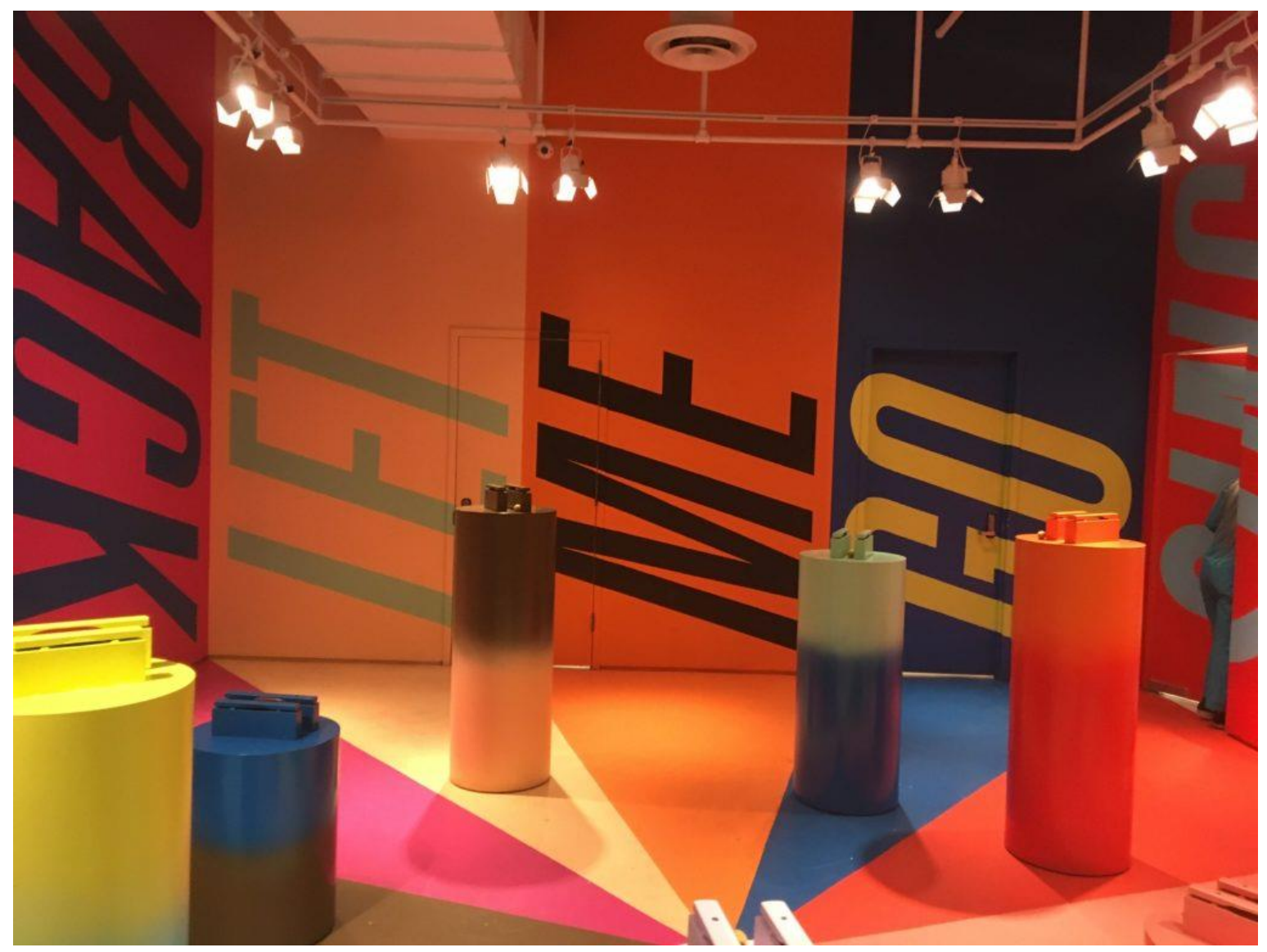

Figure 3: Interactive sound-based installation at the Color Factory, New York

Sensory media environments at the Color Factory extend beyond sound into smell and taste: the original San Francisco location featured scratch-and-sniff wallpaper (a nod to Willy Wonka, owner of a very different colourful factory), and in New York, choosing a dusty teal-coloured button from the "Wall of Buttons" led me to a room where I was offered a blue, raspberry-flavoured gummy banana and a mango-flavoured Swedish fish candy (complementary colours corresponding to the button I had chosen). The Houston location features a smell-based installation by non-profit Art \& Olfaction titled Chromorama: a circle of colourful tubes resembling industrial pipes features various verbal "clues" as to what scent the visitor will smell when leaning in and lifting a circular cap. Chromorama posits a direct correlation between colour and smell - that is, colour and the unseen origin of the scent, which are intended to activate past memories. The sea-green tube corresponds to the clue "Sand Between Your Toes" and the briny scent of the ocean, and the purple tube titled "Home Sick From School" couldn't be anything other than the smell of grape-flavoured cold medicine. Other times, however, the relationship between colour and smell is less straight-forward: red is "First Kiss" (lipstick?), pale grey, "Crying and Frying", is onions, and green, "Winning the Lottery", is cash. Chromorama recalls historical attempts at a multisensory cinematic experience, such as Smell-O-Vision, which failed in part due to their attempts to universalise sensory experience while simultaneously trying to activate individual memories. It's no coincidence that the most successful colour/smell pairings are those involving artificial colour and flavour: rather than some sort of Proustian revelry, the purple 
cold medicine smells and tastes purple in the same way that blue raspberry candy and pink lemonade evoke objects to be found nowhere in nature. They function as empty signifiers - taste and colour in the abstract with no referent to speak of.

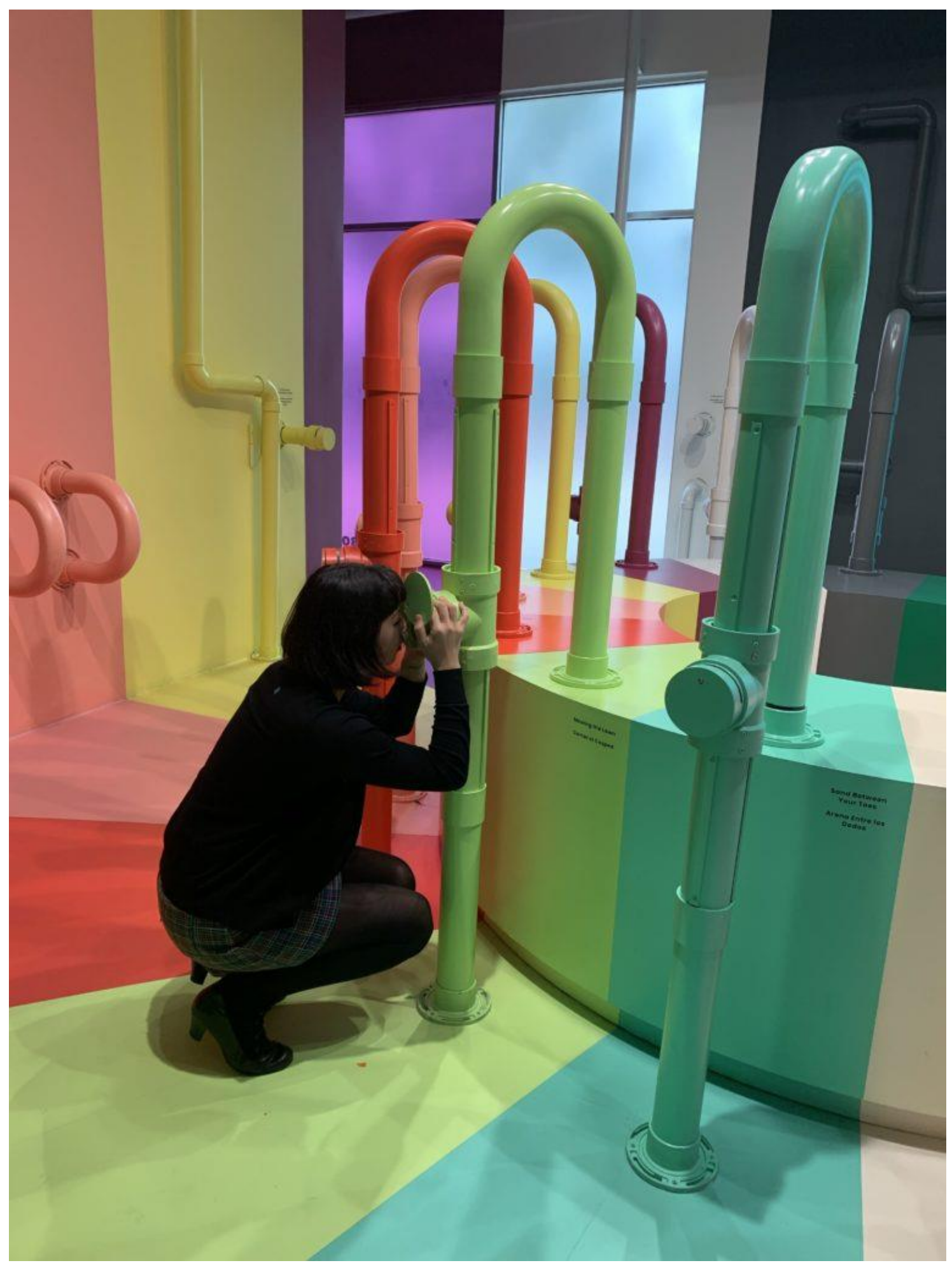

Figure 4: Chromorama, a smell-based installation by nonprofit Art \& Olfaction in Houston. 


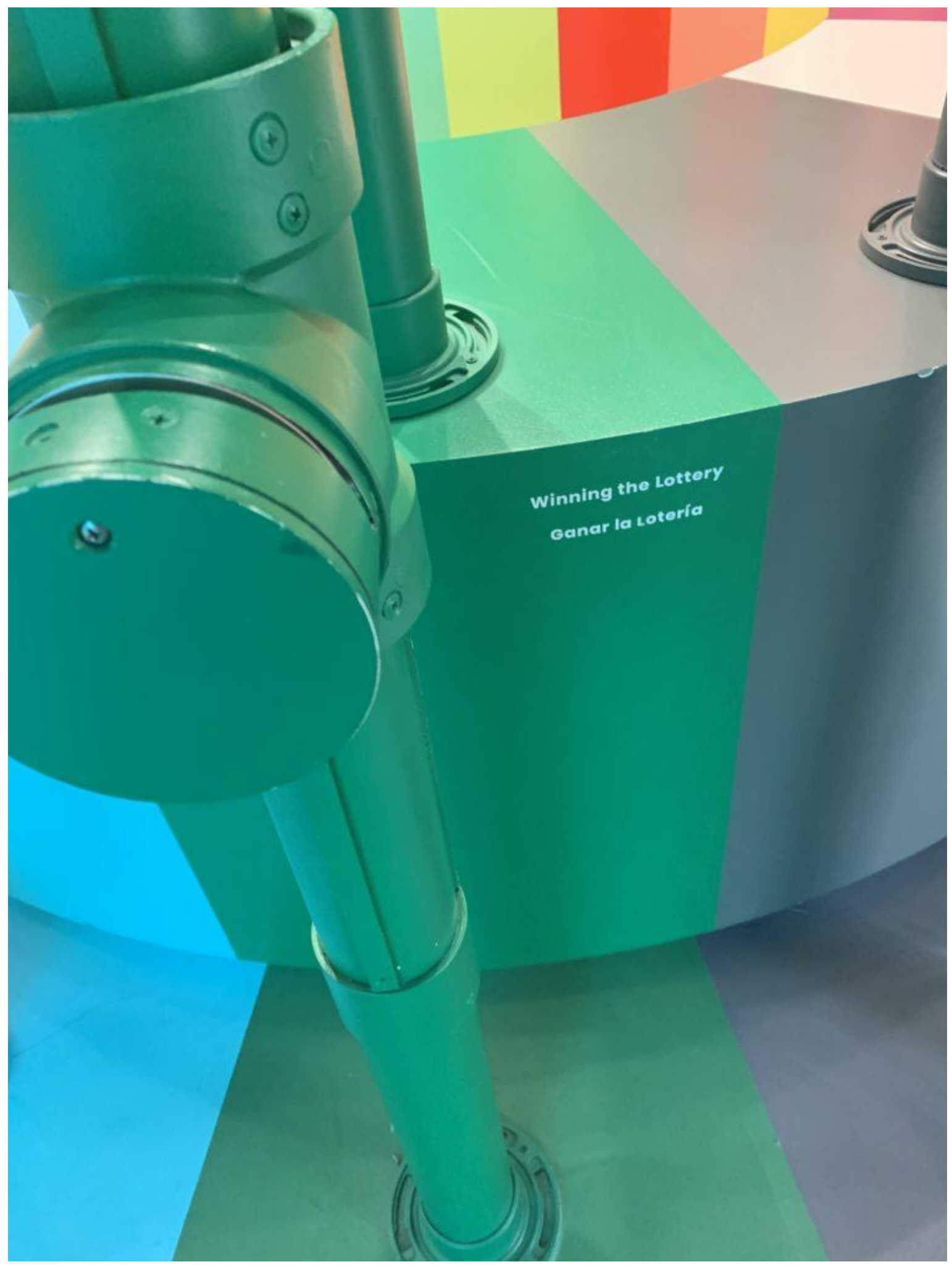

Figure 5: "Winning the Lottery," a synthetic scent meant to smell like paper money. 


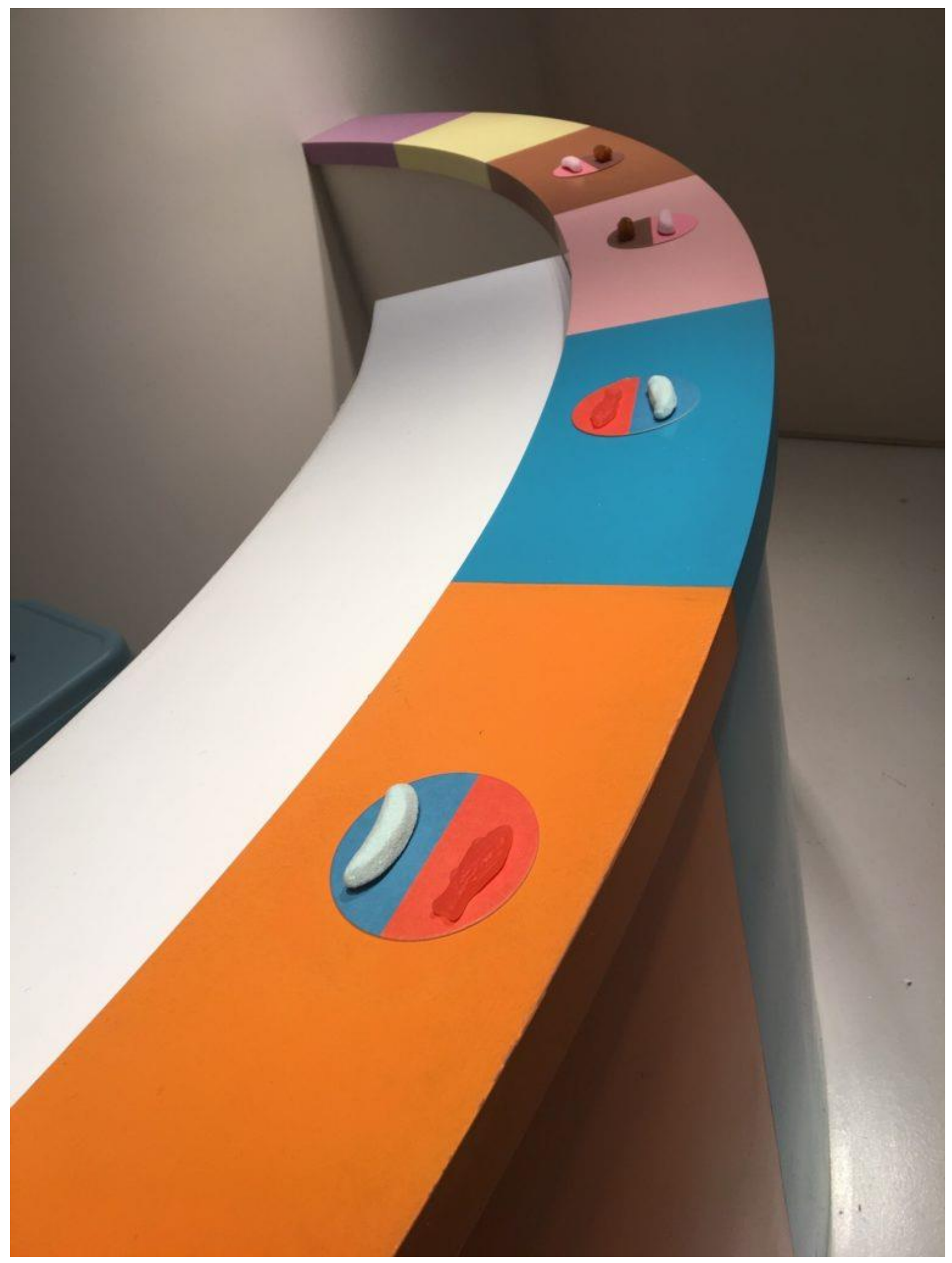

Figure 6: Complementary-coloured gummy candies in New York. 


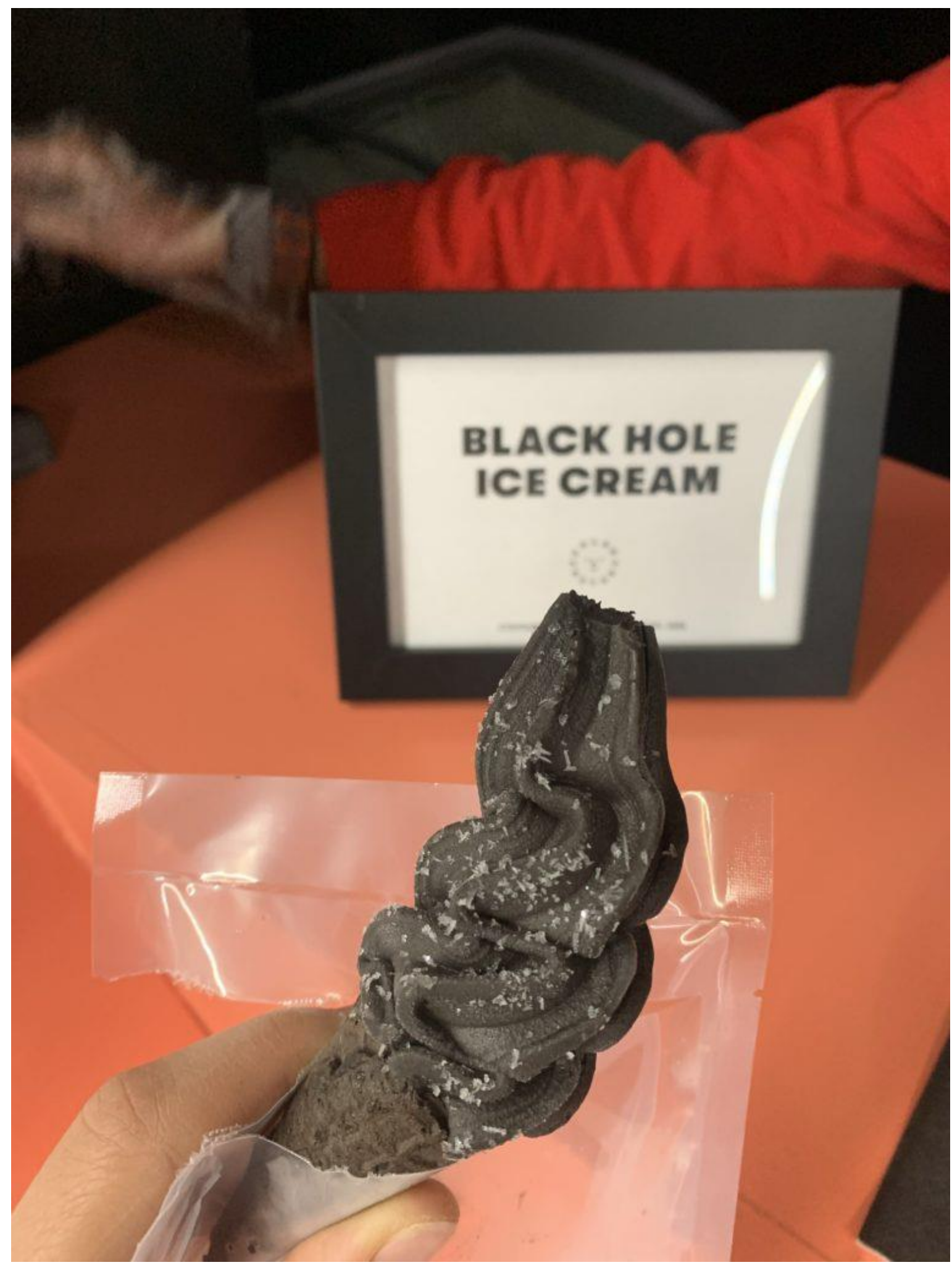

Figure 7: "Black Hole" activated charcoal ice cream is offered in conjunction with the NASA-sponsored To the Moon ball pit in Houston. 


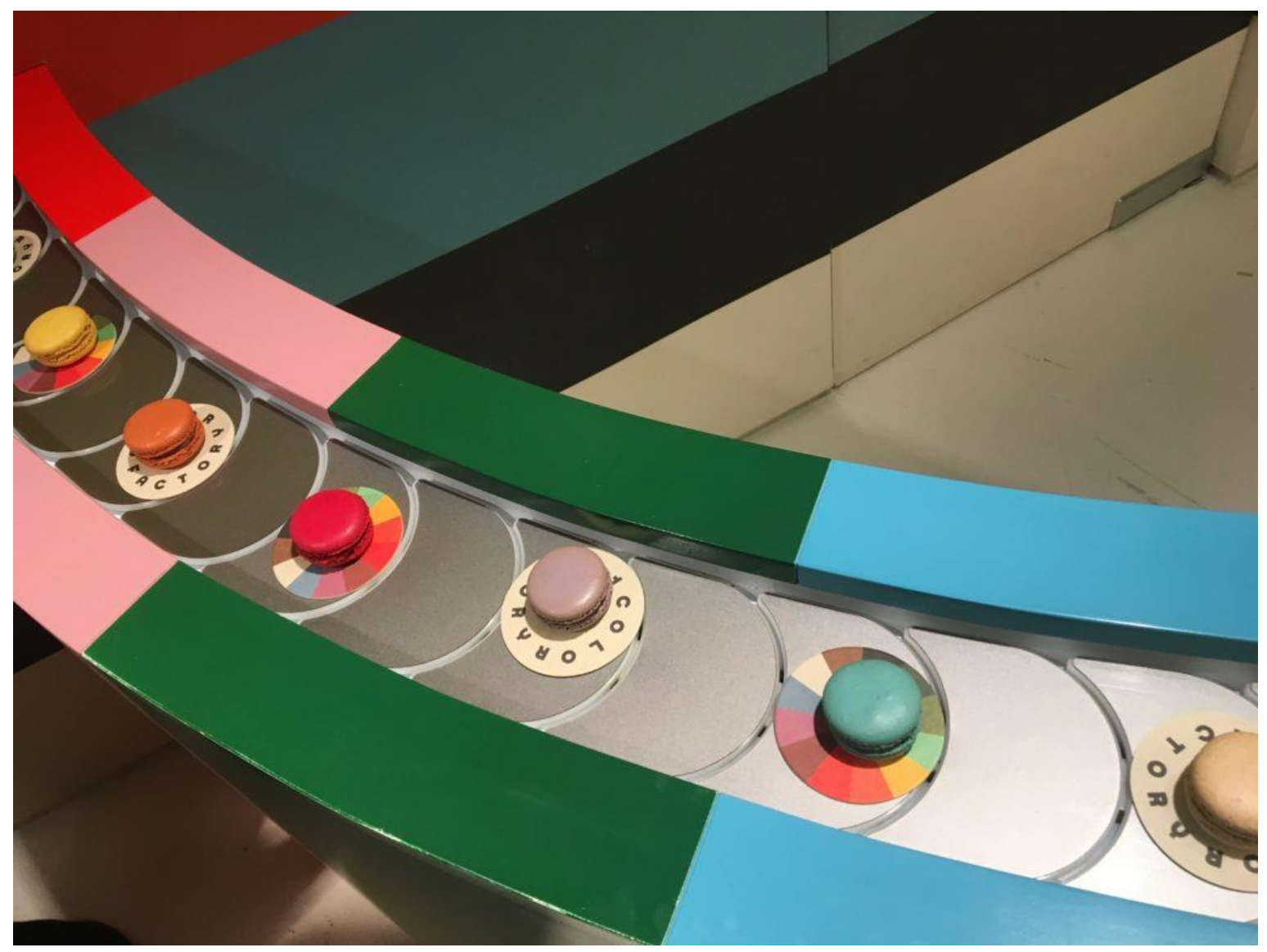

Figure 8: French macaron conveyer belt in New York

Because synesthesia creates unexpected sensory experiences that are ultimately subliminal, it is an ideal marketing tool by which to capitalise on both pleasure and attention. ${ }^{7}$ It is ultimately attention - both in a physical visit to the exhibit and by posting images to social media - that the Color Factory sells. Despite its name, what the pop-up produces isn't actually colour, but digital images of participants that ultimately find their home on photo-sharing apps. Each visitor to the Color Factory receives a card with a personalised QR code which, when swiped, activates a mounted, often concealed camera that automatically takes a hands-free photo Instagram-ready photo or Boomerang of them and sends it to their email. In today's attention economy, where value is measured not by singularity or originality, but by "eyeballs" (that is, clicks, likes, and reposts), eye-popping, high-contrast colours perform an essential role. ${ }^{8}$ While other competing pop-ups, such as the Rosé Mansion, the Museum of Ice Cream, 29Rooms, the FOMO Factory, and Room for Tea, don't explicitly take colour as their theme, the photographs they produce look strikingly similar to those taken at the Color Factory: flat, brightly saturated colours in simple geometric shapes pop against a white background, revealing that if there is one common denominator, it's not simply the commodification of experience via social media, but how these experiences are mediated through digital colour.

As new media theorists such as Carolyn Kane and Sean Cubitt have noted, because digital colours originate first and foremost as algorithms, texture, colour, and lighting on electronic screens will have 
corresponding numerical values. ${ }^{9}$ Most crucially, these numbers serve to average and standardise the colours seen on multiple screens at a massive scale: on Instagram, where 27,264 images are tagged \#colorfactoryco, ${ }^{10}$ physical colour must be reliably and seamlessly translated into numerical code. ${ }^{11}$ This means that the specific paint shades chosen for the interior are those deemed the most "photogenic," requiring the Color Factory's designers to constantly move between subtractive (pigment-based) colour and additive (light-based) colour. Prior to opening, the Color Factory's team tested out different lighting scenarios and invested in mirrorless Canon EOS RP cameras, whose autofocus feature compensates for poor lighting conditions. ${ }^{12}$ Colours that are supposedly drawn from specific locations are sampled and reduced to commercial paint swatches, abstract geometric shapes, and those that photograph the best.

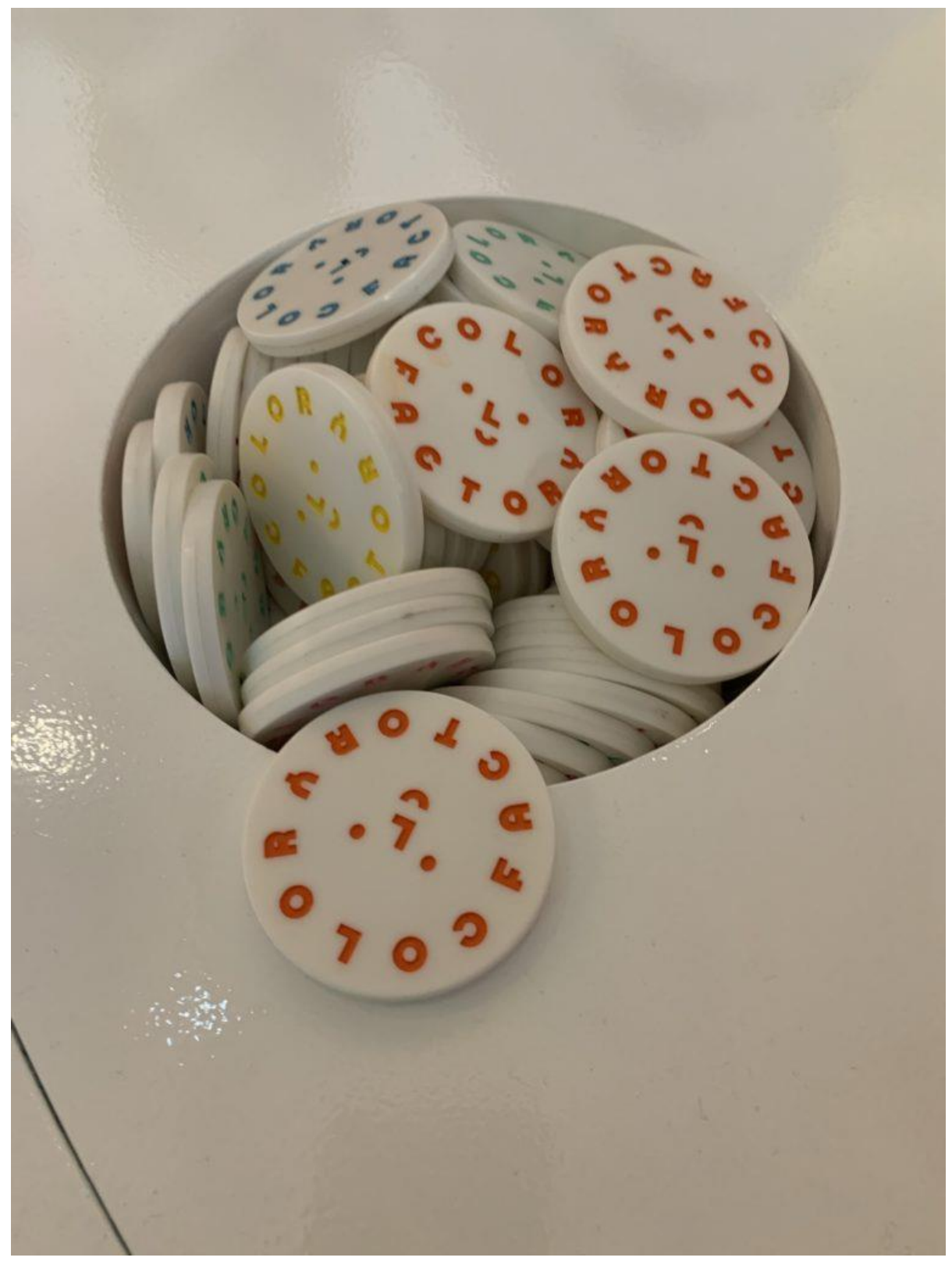

Figure 9: Scannable tokens in Houston 


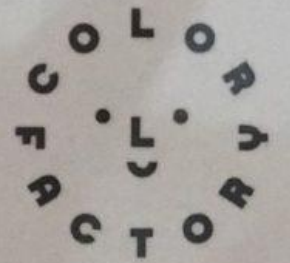

Scan this card at any photo station in Color Factory and your memories will be sent right to your inbox.

@colorfactoryco \#colorfactoryco

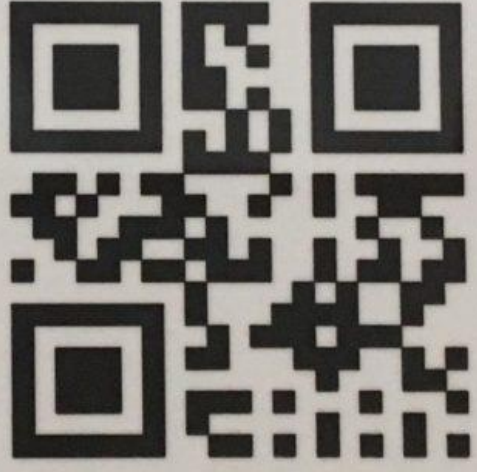

125655

Figure 10: Card with QR code in New York
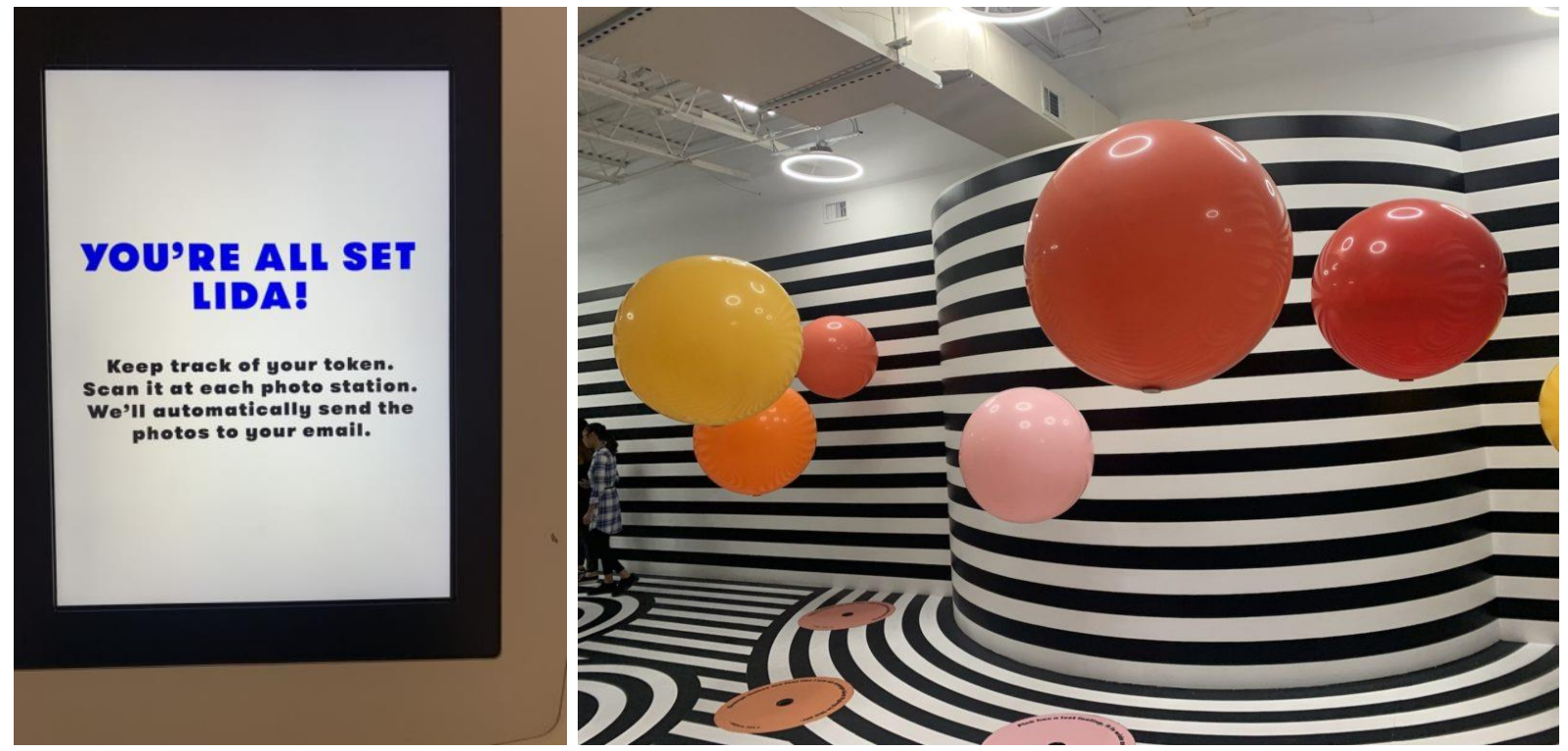

Figure 11: Confirmation email after registering email address for photos

Figure 12: Thought Bubbles installation in Houston 


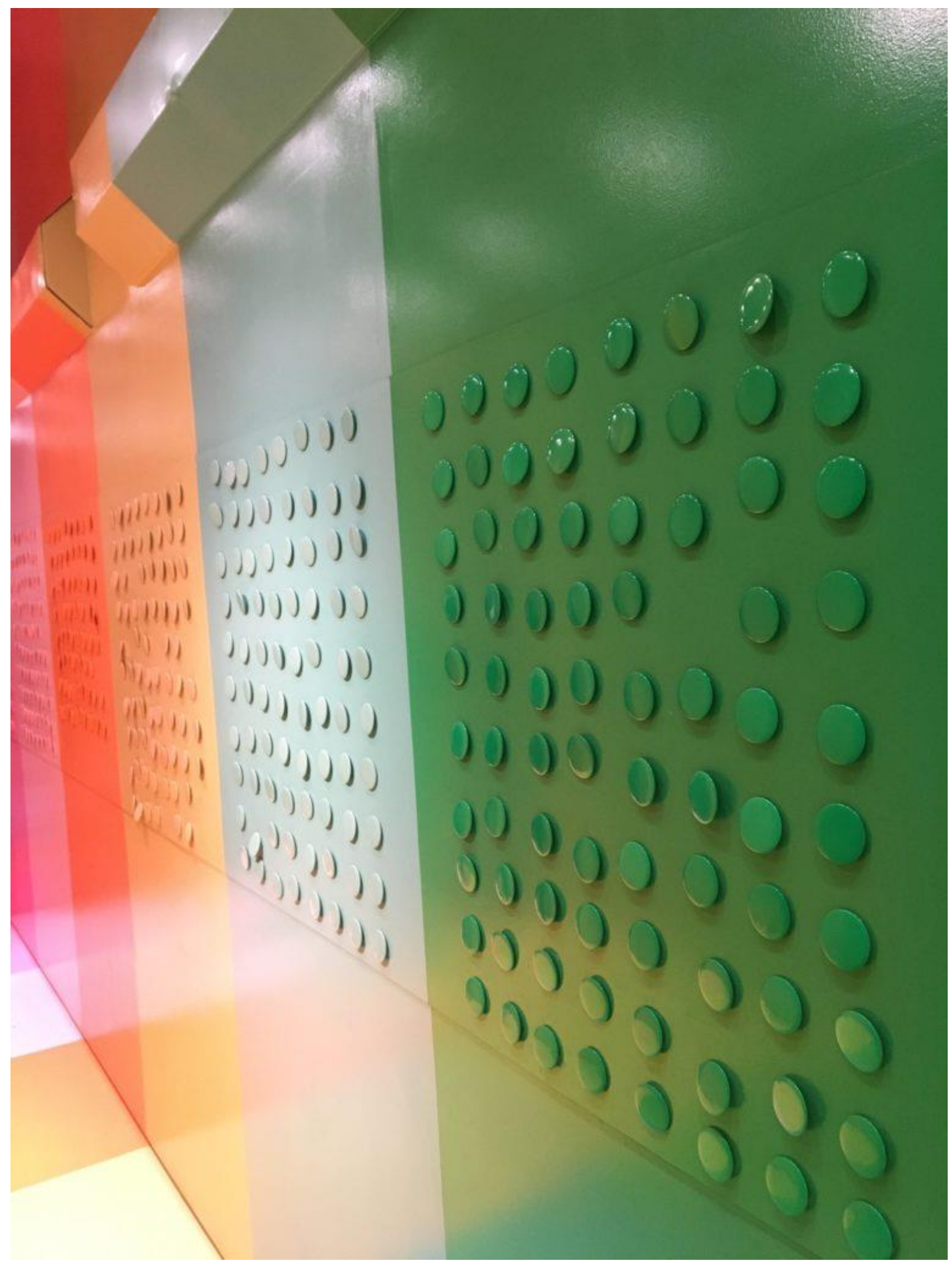

Figure 13: Wall of Buttons in New York

The Color Factory claims to be site-specific: at each location, the project collaborates with local artists and business and attempts to engage with the surrounding city, as with the Manhattan Color 
Walk in New York, installed in the garden at Cooper-Hewitt in conjunction with their exhibit "Saturated: The Allure and Science of Color". ${ }^{13}$ Visitors to the Color Factory are also given a printed "Neighborhood Map" with local "secrets," such as an ATM that doles out colourful stickers rather than cash. However, despite these nods to geographical specificity, the Color Factory ultimately presents itself as a temporary reprieve from the frenetic pace of urban life. In the tradition of the white cube gallery, the exhibition space is presented as a place where "the outside world must not come in," "windows are sealed off," and "there is no time." 14 But the Color Factory also turns the white cube on its head by having visitors wait in a lobby where ceilings, walls, and floors are a pristine white, building anticipation for visitors to move from what is essentially a blank canvas into an explosion of colour: only by entering this space do we leave the monochrome world of banal urbanism for a fantastical, synesthetic one. Though the Color Factory and its partners claim that the colours they use are drawn from specific places in New York (wall text states that the Balloon Room is meant to "[conjure] the colours you might see at sundown over the Hudson River or at sunrise, reflected against a skyscraper"), these colours are always sampled quantitively into paint swatches and geometric shapes, or those that photograph the best with an iPhone camera. The Color Factory thus functions as both a site-specific installation and a "non-place" of waiting and transition. ${ }^{15}$

At the Color Factory, there is a clear separation between self and environment in which visitors never quite belong to or inhabit its colourful interiors. Just as Dorothy steps out of monochromatic Kansas into Technicolor Oz, for an hour and half (the average amount of time at the Color Factory) and for the price of 38 or 35 dollars (depending on whether you are in New York or Houston; children 12 and under pay 28), we are invited into a fantastical play-space for adults that is, as one visitor described it, "like walking through a rainbow." Colour at the Color Factory is not meant to be atmospheric; instead, we are meant to view it as existentially separate from those who pass through the exhibition space.

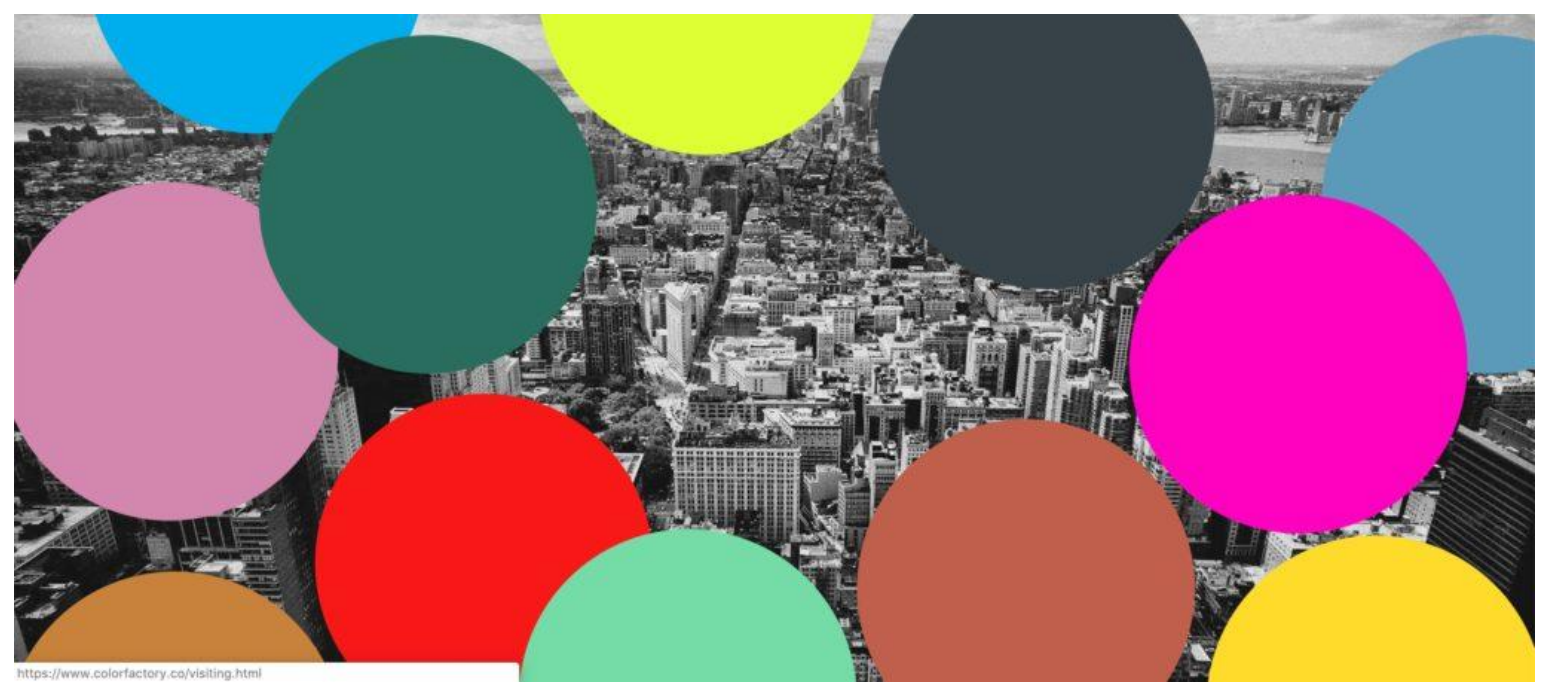

Figure 14: Still of Color Factory home page, where brightly coloured circles plaster a black-and-white photograph of New York as the page loads. 
Though official social media posts often have models coordinate their clothing with the photo background, most photographs taken at the Color Factory feature viewers wearing clothes in more subdued shades or in colours that do not match their surroundings, and the corresponding Instagram posts tagged \#colorfactoryco reflect this dissonance:

"Be a pop of color in a black and white world"

"We all need a bit of color now and again"

"Why live and dream in black and white when you can enjoy life in color?"

"Enjoyed having a little more color in my life"

By creating a clear separation between self and physical environment, the message is clear: our bodies can only become part of this space when we submit to the gaze of the cameras. While visitors consent to being photographed within the gallery space, the eventual posting of these images to social media platforms poses key questions about the relationship between colour as visual attraction on the one hand and the ubiquity of self-surveillance on the other. The cameras are designed to take photographs that visitors couldn't take themselves, using wide angle lenses and aerial shots. ${ }^{16}$ In addition to the cameras, mirrors and reflective surfaces are everywhere, making self-presentation and monitoring, rather than colour, becomes the Color Factory's primary subject. In an attention-based economy in which we must be "always on," The Color Factory forces us to participate in a "compulsory labor of self-management." "Inverting the logic of the selfie, the photos we leave the Color Factory with have a unique gaze: one that is disembodied, but paradoxically also self-reflexive. We choose how to pose and wait for the ten-second countdown before the flash, but ultimately, the gaze belongs not to us, but to the decentralised vision of social networks and tagged posts.

During my visit to Houston, my photos failed to send to my email; after asking the staff whether I could still access them, they assured me that every single image is stored off-site. These images belong to the Color Factory and can be used for promotional or other purposes. This normalization of selfsurveillance has sinister implications in a time when biometric technologies, such as facial recognition and surveillance cameras that can "see" in colour and infrared, make it easier to track and identify individuals with a precision beyond the limits of human vision ("computer vision dazzle," also known as CV dazzle, is a recent attempt to thwart facial recognition algorithms through colour and makeup). ${ }^{18}$ At the Color Factory, under the pretence of the positive emotional impact of brightly coloured media environments, the body itself becomes a computable entity, stored as data in the company's cloud. With a swipe of a QR code, we go from viewing subject to object viewed: we can only become part of the Color Factory by being converted to pixels ourselves.

1 Throughout this piece, I default to the British spelling "colour," except in direct quotes and titles that spell it "color," such as the Color Factory.

${ }^{2}$ Natalia Winkelman, “The Color Factory is Made for Instagram, but Is It Art?” The Daily Beast, August 21, 2018. https://www.thedailybeast.com/the-color-factory-is-made-for-instagram-but-is-it-art

${ }^{3}$ Mary Ann Doane, "Information, Crisis, Catastrophe." In Old Media, New Media: A History and Theory Reader, eds.

Thomas Keenan and Wendy Hui Kyong Chun (New York: Taylor \& Francis, 2004), 251.

4 Robin Young and Karyn Miller-Medzon, "Pop-Up Museum Lets Visitors Take Sensory Plunge into Wide World of Color.” WBUR: Boston’s NPR News Station, April 1, 2018. https://www.wbur.org/hereandnow/2019/04/01/colorfactory-new-york 
${ }^{5}$ Examples of sound and colour-based synaesthesia include colour organs designed by Alexander Wilfred Rimington, Alexander Scriabin, Mary Hallock Greenewalt, and Thomas Wilfred; Kandinsky's philosophy of painting, Rimbaud's poem "Voyelles"; and as abstract animations by Oskar Fischinger, Mary Ellen Bute, and Len Lye dubbed "visual music". See Polina Dimova's forthcoming book At the Crossroads of the Senses: The Synaesthetic Metaphor Across the Arts in European Modernism, as well as Chapter 3, "Synthetic Dreams: Expanded Spaces of Cinema" in Joshua Yumibe and Sarah Street, Chromatic Modernity: Color, Cinema, and Media of the 1920s (New York: Columbia University Press, 2019): 104-146.

${ }^{6}$ Joshua Yumibe and Sarah Street, Chromatic Modernity, 125.

7 David Howes, "Hyperesthesia, or, the Sensual Logic of Late Capitalism." In Empire of the Senses: The Sensory Culture Reader, ed. David Howes (New York: Berg, 2005), 293.

${ }^{8}$ Carolyn L. Kane, "GIFs That Glitch: Eyeball Aesthetics for the Information Economy." Communication Design 4 (2016): 41-62.

9 See Carolyn L. Kane, Chromatic Algorithms: Synthetic Color, Computer Art and Aesthetics After Code (Chicago: University of Chicago Press, 2014) and Sean Cubitt, The Practice of Light: A Genealogy of Visual Technologies from Prints to Pixels (Cambridge, MA: The MIT Press, 2014)

${ }^{10}$ As of May 2020

${ }^{11}$ The calibration and standardisation of colour for light-emitting screens is part of a much longer history of compression, seen most clearly in the development of photographic test cards and standards for colour television in the 1950s. See Jonathan Sterne and Dylan Mulvin, "The Low Acuity for Blue: Perceptual Technics and American Color

Television." journal of visual culture, vol. 13, no. 2 (2014): 118-138; Susan Murray, Bright Signals: A History of Color Television (Durham, NC: Duke University Press, 2018); and Claire Lehmann, "Color Goes Electric.” Triple Canopy, May 31, 2016. Online. https://www.canopycanopycanopy.com/contents/color-goes-electric/\#title-page

${ }^{12}$ Ashley Carman, "Experience, Experience, Experience! Behind Color Factory, one of the photogenic pop-ups trying to conquer the experience economy." The Verge, November 6, 2019.

https://www.theverge.com/2019/11/6/20949838/color-factory-houston-instagram-pop-up-experience-museum 13 Saturated ran until March 2019. https://www.cooperhewitt.org/channel/saturated/

${ }^{14}$ Brian O'Doherty, Inside the White Cube: The Ideology of the Gallery Space (Berkeley: University of California Press, 1976)

${ }^{15}$ See Marc Augé, Non-places: Introduction to an Anthropology of Supermodernity, trans. John Howe (Brooklyn: Verso, 1995)

${ }^{16}$ Ashley Carman, "Experience, Experience, Experience!"

${ }^{17}$ Jonathan Crary, 24/ 7: Late Capitalism and the Ends of Sleep (Brooklyn: Verso, 2013), 46.

${ }^{18}$ See Adam Harvey, “Computer Vision Dazzle (Camouflage).” Last updated June 3, 2020. https://cvdazzle.com/

\section{Bibliography}

Augé, Marc. Non-places: Introduction to an Anthropology of Supermodernity, trans. John Howe (Brooklyn: Verso, 1995)

Carman, Ashley. "Experience, Experience, Experience! Behind Color Factory, one of the photogenic pop-ups trying to conquer the experience economy." The Verge, November 6, 2019. https://www.theverge.com/2019/11/6/20949838/color-factory-houston-instagram-pop-upexperience-museum

Color Factory. https://www.colorfactory.co

Crary, Jonathan. 24 /7: Late Capitalism and the Ends of Sleep (Brooklyn: Verso, 2013)

Cubitt, Sean. The Practice of Light: A Genealogy of Visual Technologies from Prints to Pixels (Cambridge, MA: The MIT Press, 2014)

Doane, Mary Ann. "Information, Crisis, Catastrophe." In Old Media, New Media: A History and Theory Reader, eds. Thomas Keenan and Wendy Hui Kyong Chun (New York: Taylor \& Francis, 2004): 251-264. 
Harvey, Adam. “Computer Vision Dazzle (Camouflage).” Last updated June 3, 2020. https://cvdazzle.com/

Hess, Amanda. “The Existential Void of the Pop-Up 'Experience." The New York Times, September 26, 2018.

Howes, David. "Hyperesthesia, or, the Sensual Logic of Late Capitalism." In Empire of the Senses: The Sensory Culture Reader, ed. David Howes (New York: Berg, 2005): 281-303.

Kane, Carolyn L. Chromatic Algorithms: Synthetic Color, Computer Art and Aesthetics After Code (Chicago: The University of Chicago Press, 2014)

"GIFs That Glitch: Eyeball Aesthetics for the Information Economy." Communication Design 4 (2016): 41-62.

Lehmann, Claire. “Color Goes Electric.” Triple Canopy, May 31, 2016. Online.

https://www.canopycanopycanopy.com/contents/color-goes-electric/\#title-page

Murray, Susan. Bright Signals: A History of Color Television (Durham, NC: Duke University Press, 2018)

Odell, Jenny. How to Do Nothing: Resisting the Attention Economy (Melville House, 2019)

O'Doherty, Brian. Inside the White Cube: The Ideology of the Gallery Space (Berkeley: The University of California Press, 1976)

"Saturated: The Allure and Science of Color." Cooper Hewitt Smithsonian Design

Museum. https://www.cooperhewitt.org/channel/saturated/

Sterne, Jonathan and Dylan Mulvin, "The Low Acuity for Blue: Perceptual Technics and American Color Television." journal of visual culture, vol. 13, no. 2 (2014): 118-138.

Winkelman, Natalia. "The Color Factory is Made for Instagram, but Is It Art?" The Daily Beast, August 21, 2018. https://www.thedailybeast.com/the-color-factory-is-made-for-instagram$\underline{\text { but-is-it-art }}$

Young, Robin and Karyn Miller-Medzon, "Pop-Up Museum Lets Visitors Take Sensory Plunge into Wide World of Color.” WBUR: Boston's NPR News Station, April 1, 2018. https://www.wbur.org/hereandnow/2019/04/01/color-factory-new-york

Yumibe, Joshua and Sarah Street, Chromatic Modernity: Color, Cinema, and Media of the 1920s (New York: Columbia University Press, 2019)

\section{About the Author}

Lida Zeitlin Wu is a PhD candidate in Film \& Media at the University of California, Berkeley, where she works on colour technologies, media theory, and the politics of visual culture. Her 
dissertation, "Seeing By Numbers: Color Systems and the Digitization of Perception," traces how colour systems - diagrams and models that attempt to encompass the full range of human colour vision - came to play a key role in engineering perception over the course of the twentieth century. Lida's writing has been published in Adaptation: The Journal for Literature on Screen Studies, The Nabokov Online Journal, The Art Newspaper China, and LEAP, China's bilingual contemporary art magazine. 